\title{
The Efficacy of P2Y12 Reactive Unit to Predict the Periprocedural Thromboembolic and Hemorrhagic Complications According to Clopidogrel Responsiveness and Safety of Modification of Dual Antiplatelet Therapy : A Meta-Analysis
}

\author{
Hyun Jung Kim, Jae Sang Oh, ${ }^{2}$ Sukh Que Park, ${ }^{3}$ Seok Mann Yoon, ${ }^{2}$ Hyeong Sik Ahn, Bum Tae Kim ${ }^{4}$ \\ Department of Public Health,' Graduate School of Korea University, Seoul, Korea \\ Department of Neurosurgery, ${ }^{2}$ Soonchunhyang University Cheonan Hospital, Soonchunhyang University College of Medicine, Cheonan, Korea \\ Department of Neurosurgery, ${ }^{3}$ Soonchunhyang University Seoul, Hospital, Soonchunhyang University College of Medicine, Seoul, Korea \\ Department of Neurosurgery, ${ }^{4}$ Soonchunhyang University Bucheon Hospital, Soonchunhyang University College of Medicine, Bucheon, Korea
}

The efficacy of P2Y12 reaction unit (PRU) of VerifyNow still remains as a controversial issue in neurointervention. So we investigated the usefulness of PRU of VerifyNow to predict the peri-procedural thromboembolic events (TE) and hemorrhagic events (HE). And we evaluated the safety of modified dual antiplatelet therapy (DAPT) or triple antiplatelet therapy (TAPT) for clopidogrel hyporesponders. We searched MEDLINE, EMBASE, the Cochrane Central Register of Controlled Trials, Web of Science and Scopus on August 19 2018. Data was collected the 1) incidence of TE between clopidogrel responder and clopidogrel hypo-responder, 2) incidence of HE between clopidogrel hyper-responder and clopidogrel responder and hypo-responder, and 3) incidence of TE and HE between modified DAPT or TAPT and standard DAPT in clopidogrel hypo-responder. High cut-off value of PRU was defined as PRU $>40 \%$ or $<220$. Fifteen studies were enrolled. Clopidogrel responder showed lower incidence of TE than hypo-responder (risk ratio [RR], $0.32 ; 95 \%$ confidence interval [Cl], $0.17-0.61 ; p<0.001$ ). With the high cut-off value of PRU, clopidogrel responder showed more lower incidence of TE than hypo-responder ( $\mathrm{RR}, 0.11 ; 95 \% \mathrm{Cl}, 0.02-0.45 ; p=0.002)$. The incidence of periprocedural $\mathrm{HE}$ have higher on clopidogrel hyper-responder than clopidogrel responder and hypo-responder ( $\mathrm{RR}, 4.26 ; 95 \% \mathrm{Cl}, 1.10-16.44 ; p=0.04$; $I^{2}=66 \%$ ). The incidence of periprocedural TE after changing regimen of DAPT for clopidogrel hypo-responder have a tendency to reduce, but there was no significant difference between modified DAPT or TAPT group and standard DAPT group $(p>0.05)$. The incidence of periprocedural HE after changing regimen of DAPT for clopidogrel hypo-responder was no significant difference between modified DAPT or TAPT group and standard DAPT group ( $p>0.05$ ). PRU is a useful tool as a predictor of peri-procedural TE or HE on neurointervention. PRU has a threshold effect of cut-off value to predict the peri-procedural TE. Modified DAPT or TAPT to prevent TE in clopidogrel hypo-responders could not reduce the incidence of TE. We should investigate the further research about modification of regiment on neurointervention.

Key Words : Aneurysm · Thromboembolism · Hemorrhage · Clopidogrel · Blood platelets · P2Y12 reaction unit.

- Received : March 27, 2019 •Revised : June 20, 2019 •Accepted : August 7, 2019

- Address for reprints : Jae Sang Oh

Department of Neurosurgery, Soonchunhyang University Cheonan Hospital, Soonchunhyang University College of Medicine, 31 Suncheonhyang 6-gil, Dongnam-gu, Cheonan 31151 , Korea

Tel : +82-41-570-3652, Fax : +82-41-572-9297, E-mail : metatron1324@hotmail.com, ORCID : https://orcid.org/0000-0003-4570-6763

This is an Open Access article distributed under the terms of the Creative Commons Attribution Non-Commercial License (http://creativecommons.org/licenses/by-nc/4.0) which permits unrestricted non-commercial use, distribution, and reproduction in any medium, provided the original work is properly cited. 


\section{INTRODUCTION}

Thromboembolic events (TE) in neurointervention are the most common complications and often result in severe morbidity and mortality ${ }^{30)}$. Dual antiplatelet premedication therapy (DAPT) is considered as a practical method to reduce the peri-procedural TE. Even if stent-assisted coiling is not performed for an unruptured aneurysm, DAPT (100 mg of aspirin and $75 \mathrm{mg}$ of clopidogrel bisulfate daily) is recognized as a standard regimen to reduce the $\mathrm{TE}^{8)}$.

Currently, VerifyNow ${ }^{\mathrm{TM}}$ Assay (Accumetrics, San Diego, CA, USA) is used worldwide as an effective and straightforward diagnostic tool to examine the degree of responsiveness to clopidogrel treatment. Several studies have reported that high P2Y12 reaction unit (PRU) level could predict the TE during the peri-procedural stage and there are significantly high prevalence (40-50\%) of the proportion of clopidogrel hypo-responders, who have high PRU level despite taking the DAPT for a sufficient period of time ${ }^{12,20,31)}$. In addition, it has been reported that the prophylactic therapy of clopidogrel may induce an increase in the hemorrhagic events (HE) in patients with low PRU level ${ }^{38}$.

Recently, several studies have reported that modified DAPT (use of loading dose of clopidogrel or replacement of drug from clopidogrel to prasugrel) or triple antiplatelet therapy (new regimen with the addition of cilostazol to DAPT) for clopidogrel hypo-responders is effective in reducing peri-procedural $\mathrm{TE}^{12,19,23,38)}$. However, it still remains as a controversial issue in neurointervention. Therefore, we investigated the usefulness of PRU level, which was checked before the procedure, as a tool to predict the peri-procedural complications (TE or HE). Also, we studied clinical effectiveness and safety about new regimen as modified DAPT or TAPT before performing the procedure in clopidogrel hypo-responders.

\section{METHODS}

We used multiple comprehensive databases to evaluate 1) the validity of PRU for predicting the peri-procedural TE \& HE. 2) the safety and efficacy of modified DAPT or TAPT on clopidogrel hypo-responders based on PRU test before the initiation of the procedure. This study is based on the Cochrane Review Methods ${ }^{1}$.

\section{Data source \& literature source}

We searched MEDLINE, EMBASE, the Cochrane Central Register of Controlled Trials (CENTRAL) Web of Science and Scopus on August 19 2018. We set no restrictions on language or year of publication in our search. And if publications were not underwent on English, translation to English was done.

The following keywords and MeSH were searched through Medline : aneurysm, stents, aspirin, clopidogrel, and platelet aggregation inhibitors. See Supplementary material for the comprehensive list. Search strategies were adapted for other databases based on the MEDLINE strategy. After the initial electronic search, we hand-searched further relevant articles and the bibliographies from identified studies. Articles identified were assessed individually for inclusion in the present study.

\section{Study selection}

The inclusion of the search results was independently decided by two reviewers (JS Oh and HJ Kim) based on the selection criteria. Study selection was made through two levels of screening: At the first level, we screened titles and abstracts of identified studies. At the second level, we screened the full text. Studies were included in our meta-analysis if they included all the four factors; 1 ) description of the results of PRU for clopidogrel response on neurointervention, 2) description of the clinical results of peri-procedural TE and HE of neurointervention. Neurointervention comprising of stent-assisted coil embolization and extracranial or intracranial stenting were included, 3) description of the pre-medication with aspirin, clopidogrel, cilostazol, and prasugrel, and 4) were published in all languages. Studies were excluded from our study if they included at least one; 1) they reported about the only use of fow-diver stent, 2) another test method other than VerifyNow for examination of antiplatelet reactivity, 3) other antiplatelets or anticoagulants (ticagrelor, glycoprotein IIb/IIIa inhibitors, etc.), and 4) studied without patients who performed onstent-assisted coil embolization.

TE were defined as 1) in-stent thrombus or newly developing thrombus in parent artery in neurointervention during the peri-procedural period, or 2) cerebral infarction diagnosed clinically or by neuroimaging within one month after the procedure and associated neurological deterioration. But, the non-symptomatic silent emboli on brain magnetic resonance imaging were excluded ${ }^{22}$. HE was defined as the events which 
occurred during the peri-procedural period according to Thrombolysis in Myocardial Infarction bleeding criteria within 30 days after neurointervention ${ }^{27}$. The peri-procedural period was defined as the time from the initiation of the procedure to one month after neurointervention. Table 1 showed the new grouping for meta-analysis on this current study. To evaluate the differences in the clinical outcome according to the degree of PRU level (value or inhibition \%), we divided Inhibition group into the three subgroups; 1) moderate-inhibition group defined as patients who involved in a group with low cut-off value of PRU $\geq 20 \%$ or $\leq 240$ after DAPT therapy, 2) high-inhibition group defined as patients who involved in a group with high cut-off value of PRU $>40 \%$ or $<220$ after DAPT therapy, and 3) very high-inhibition group defined as patients who involved in a group with high cut-off value of PRU $>74 \%$ or $<175$ PRU value. We divided the patients who enrolled on study of the efficacy of PRU to predict peri-procedural TE into two groups as Inhibition group and No-inhibition group to evaluate the difference in the incidence of TE between two groups. And we divided the patients who enrolled on study of the efficacy of PRU to predict peri-procedural HE into two groups as inhibition group+no-inhibition group and very high-inhibition group. To evaluate the safety and availability of modified DAPT or TAPT for the no-inhibition group, we investigated the incidence of peri-procedural TE and HE between modified DAPT or TAPT group and standard DAPT group

\section{DATA EXTRACTION}

The two reviewers independently extracted data from each study using a predefined data extraction form. Any disagreement unresolved based on discussion was further reviewed by a third author.

The following variables were extracted from the studies :
1) citation information (author and publication year), 2) demographic, clinical, and treatment characteristics (e.g., total sample size and number of patients in the intervention and control groups), 3) the purpose and site of stent deployment (stent-assisted coil embolization, extracranial carotid stenting, and intracranial stenting), 4) cut-off value of PRU or inhibition percentage (\%) in VerifyNow assay, and 5) the incidence of TE and HE included during peri-procedural period (from initiation of procedure to one month of post-procedural period).

The main outcome of our review was the differences in 1) the incidence of peri-procedural TE between inhibition group and no-inhibition group after proper clopidogrel medication, 2) the incidence of peri-procedural HE between inhibition group+no-inhibition group and very high-inhibition group after proper clopidogrel medication, 3) the incidence of peri-procedural TE between modified DAPT or TAPT group to change the regimen for the no-inhibition group and standard DAPT group, and 4) the incidence of peri-procedural HE between modified DAPT or TAPT group to change the regimen for no-inhibition group and standard DAPT group. Incidence was expressed as a number (n). If data did not describe insufficient in article, we sent the e-mail to corresponding author and then detailed data was obtained.

\section{ASSESSMENT OF METHODOLOGICAL QUALITY}

Two reviewers (J.S.O. and H.J.K.) independently assessed the methodological qualities for each study using the Newcastle-Ottawa quality assessment scale to assess the risk of bias in cohort and case-control studies (Supplementary Table 1$)^{16)}$. Publication bias was assessable in a study of TE between noinhibition group and inhibition group (result 1). As our analysis with 10 studies, there was no definite publication bias in this current study (Supplementary Fig. 1).

Table 1. Grouping for meta-analysis according to cut-off level of PRU on VerifyNow assay

\begin{tabular}{|c|c|c|c|c|}
\hline Cut-off level of PRU & $>74 \%$ or $<175$ & $>40 \%$ or $<220$ & $\leq 20 \%$ or $\geq 240$ & $<20 \%$ or $>240$ \\
\hline Traditional grouping & Clopidogrel hyper-responder & \multicolumn{2}{|c|}{ Clopidogrel Responder } & Clopidogrel hypo-responder \\
\hline \multirow[t]{2}{*}{ New grouping for analysis } & Very high-inhibition group & \multicolumn{2}{|c|}{ Inhibition group } & No-inhibition group \\
\hline & & High-inhibition cut-off & Moderate-inhibition cut-off & \\
\hline
\end{tabular}

PRU : P2Y12 reaction unit 


\section{STATISTICAL ANALYSIS}

We conducted pooled analyses using the Mantel-Haenszel method with random effects weighting for meta-analyses. For binary outcomes, we calculated relative risks between the groups and 95\% confidence intervals (CIs). We included outcomes reported by multiple studies that were sufficiently similar to justify our combination of results. We estimated patient outcome measures after excluding studies with lower methodological quality or abstract only studies to check any changes in the results. If there were no significant changes in the results after excluding low-quality studies (abstract only study), then they were considered to be robust. If there were changes in the results or differences in the conclusions, then they were considered to have low stability. To estimate heterogeneity, we estimated the proportion of between-study inconsistency due to the presence of true differences between the studies (rather than the differences due to random error or chance) using the $\mathrm{I}^{2}$ statistic, with values of $25 \%, 50 \%$, and $75 \%$ considered as low, moderate, and high, respectively. We used Review Manager (RevMan; Computer program), version 5.3 (The Nordic Cochrane Centre, The Cochrane Collaboration, Copenhagen, 2014) for these analyses.

\section{RESULTS}

Searches of the databases resulted in 18997 articles. Of these publications, 18848 articles were excluded as it was clear from the title and abstract that they did not fulfill the selection criteria. For the remaining 150 articles, we obtained full manuscripts and reviewed based on the scrutiny. Finally, fifteen potentially relevant studies were identified (Fig. 1).

We included a total of 1826 cases in the present study (Table 2). Of these, 1473 cases (81\%) were of intracranial aneurysmal coiling, 241 cases $(16 \%)$ were of extracranial carotid stenting, and 112 cases $(46 \%)$ were of intracranial stenting. Inhibition percentage of PRU was defined variously as percent inhibition as less than $20 \%$ in three studies, less than $26 \%$ in one study, and less than $40 \%$ in three studies. Inhibition value of PRU was also defined variously as more than $175^{28)}, 180^{38)}, 213^{19)}, 220^{23)}, 230^{2)}$, $240^{35)}$, and $285^{20)}$ in each study. Very high inhibition level of PRU was defined as percent inhibition of more than $74 \%{ }^{21)}$ in one study and less than $120^{38)}$ of PRU value in one study.

\section{Result 1. The incidence of TE between inhibition group and no-inhibition group (Fig. 2)}

Eleven studies reported about the incidence of TE. However, a study by Prabhakaran et al. ${ }^{31)}$ was excluded as the number of TE was 0 in both inhibition group and no-inhibition group. Finally, 10 studies were enrolled in the meta-analysis. A cutoff level of PRU for inhibition of platelet was defined as inhibition percentage less than 20\%,26\%, and $40 \%$ or as PRU value more than 213,230, 240, and 285. Based on the analysis result of 10 studies, inhibition group showed the statistically lower incidence of TE than no-inhibition group (risk ratio [RR], 0.32; 95\% CI, 0.17-0.61; $p<0.001 ; \mathrm{I}^{2}=3 \%$ ).

As cut-off value or inhibition percentage was different in each study, subgroup analysis was performed according to the cut-off value of inhibition degree. Studies by Asai et al. ${ }^{2)}$ (230), Kashiwazaki et al. ${ }^{21)}$ (26\%), Drazin et al. ${ }^{10)}(20 \%)$, Kang et al. ${ }^{20)}$ (285), Kim et al. ${ }^{24)}$ (240), Nordeen et al. ${ }^{29)}$ (20\%), and Song and Shin $^{35)}$ (240) were included in the Moderate-inhibition cut-off

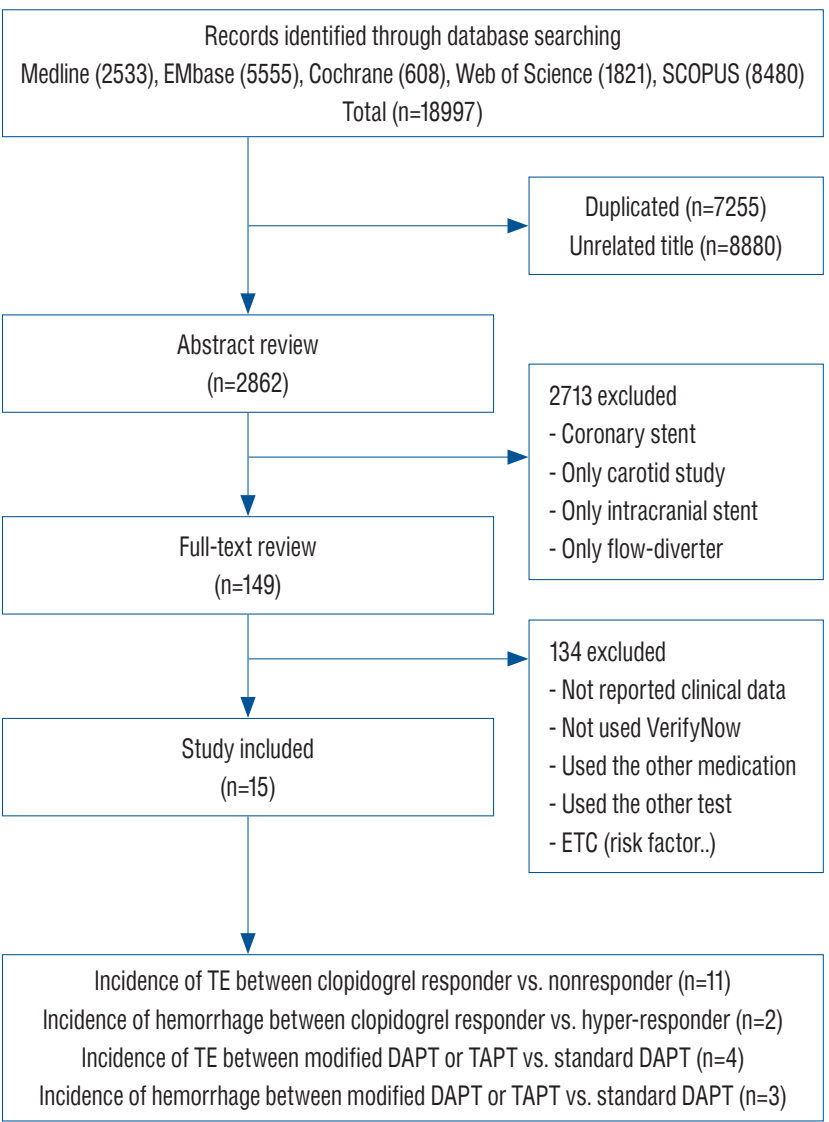

Fig. 1. Flow diagram showing the process of study selection. TE : thromboembolic events, DAPT : dual antiplatelet therapy, TAPT : triple antiplatelet therapy. 
group $\geq 20 \%$ or $\leq 240)$. The studies by Lee et al. ${ }^{25)}$ (40\%), Ryu et al. ${ }^{34)}$ (40\%), and Hwang et al. ${ }^{19)}$ (213) were included in the high-inhibition cut-off group $(>40 \%$ or $<220)$ as they had relatively high inhibition value for clopidogrel. In a subgroup analysis of according to moderate-inhibition cut-off value, inhibition group showed the statistically lower incidence of TE than no-inhibition group (RR, 0.43; 95\% CI, 0.21-0.89; $p=0.02 ; \mathrm{I}^{2}=8 \%$ ). In high-inhibition cut-off group, inhibition group showed statistically lower incidence of TE than no-inhibition group (RR, 0.11; 95\% CI, 0.02-0.45; $p=0.002, \mathrm{I}^{2}=0$ ).

\section{Result 2. The incidence of the HE between very high-inhibition group and inhibition group+no- inhibition group (Fig. 3)}

The result of HE between the two groups was based on two studies. Very high-inhibition group $(>74 \%$ or $<175)$ showed the statistically higher incidence of HE compared to inhibition group+no-inhibition group (RR, 4.26; 95\% CI, 1.10$\left.16.44 ; p=0.04 ; \mathrm{I}^{2}=66 \%\right)$.

\section{Result 3. The incidence of thromboembolic events between modified DAPT or TAPT group and stan- dard DAPT group for no-inhibition group (Fig. 4)}

TE result according to different regimen was four studies. The cut-off value of PRU for clopidogrel resistance was de-

Table 2. Summary of basic characteristics of 15 studies included in the meta-analysis

\begin{tabular}{|c|c|c|c|c|c|c|c|c|c|c|}
\hline & \multirow[b]{2}{*}{ Study } & \multirow[b]{2}{*}{ Country } & \multirow{2}{*}{$\begin{array}{l}\text { Total } \\
\text { cases }\end{array}$} & \multicolumn{3}{|c|}{ Procedure type } & \multirow{2}{*}{$\begin{array}{l}\text { Cut-off in } \\
\text { PRU }\end{array}$} & \multirow[b]{2}{*}{ Mean age (years) } & \multirow[b]{2}{*}{ Female } & \multirow[b]{2}{*}{ DM } \\
\hline & & & & $\begin{array}{l}\text { Aneurysmal } \\
\text { coiling }\end{array}$ & ECS & ICS & & & & \\
\hline 1 & Lee et $\mathrm{al}^{25)}(2008)$ & Korea & 98 & 62 & 17 & 19 & $40 \%$ & $59.1 \pm 15.8$ & 72 & $\mathrm{NE}$ \\
\hline 2 & $\begin{array}{l}\text { Prabhakaran et al. }{ }^{31)} \\
\text { (2008) }\end{array}$ & America & 74 & 57 & 5 & 12 & $40 \%$ & NE & $\mathrm{NE}$ & 6 \\
\hline 3 & Kang et al. ${ }^{20)}(2010)$ & Korea & 186 & 186 & 0 & 0 & 285 & $58.3 \pm 10.2$ & 129 & 15 \\
\hline 4 & Ryu et al. ${ }^{34)}(2010)$ & Korea & 53 & 28 & 18 & 7 & $40 \%$ & $60.3 \pm 12$ & 29 & 13 \\
\hline 5 & Drazin et al. ${ }^{10)}(2010)$ & America & 52 & 28 & 13 & 11 & $<20 \%$ & $\begin{array}{l}\text { Total 62.6 } \pm 14.0 \text {; responder }(68.3 \pm 8.6) \\
\text { hypo-responder }(59.4 \pm 15.6)\end{array}$ & 32 & 15 \\
\hline 6 & $\begin{array}{l}\text { Nordeen et al. }{ }^{29)} \\
\text { (2013) }\end{array}$ & America & 81 & 40 & 0 & 41 & $<20 \%$ & $\begin{array}{l}\text { Responder }(66 \pm 13.1) \text {; hypo-responder } \\
\quad(61 \pm 14.3)\end{array}$ & 48 & 21 \\
\hline 7 & Fifi et al. ${ }^{12)}(2013)$ & America & 96 & 27 & 53 & 16 & $<20 \%$ & $63.9 \pm 13.6$ & 40 & 32 \\
\hline 8 & $\begin{array}{l}\text { Kashiwazaki et al. }{ }^{21)} \\
\text { (2014) }\end{array}$ & Japan & 66 & 31 & 35 & 0 & $26 \%, 74 \%$ & $63.1 \pm 12.7$ & 23 & 22 \\
\hline 9 & $\begin{array}{l}\text { Hwang et al. } \\
\text { (2015) }\end{array}$ & Korea & 228 & 228 & 0 & 0 & 126 & $\begin{array}{l}\text { DAPT for hypo-responder (59.6 } \pm 8.68) \\
\text { TAPT for hypo-responder }(59.7 \pm 9.21)\end{array}$ & 108 & 24 \\
\hline 10 & Asai et al. ${ }^{2)}(2015)$ & Japan & 189 & 189 & 0 & 0 & 230 & $\begin{array}{l}\text { Responder }(59.5 \pm 10.2) ; \text { hypo- } \\
\text { responder }(60.6 \pm 11.3)\end{array}$ & 129 & 19 \\
\hline 11 & Nishi et al. ${ }^{28)}(2015)$ & Japan & 279 & 174 & 105 & 0 & $<175$ & $64.7 \pm 12.5$ & 136 & 72 \\
\hline 12 & Wong et al. ${ }^{38)}(2015)$ & America & 130 & 108 & 0 & 22 & $>180,<120$ & $56.3 \pm 12.4$ & 94 & 16 \\
\hline 13 & $\begin{array}{l}\text { Song and } \text { Shin }^{35)} \\
(2017)\end{array}$ & Korea & 93 & 93 & 0 & 0 & 240 & Age $>60$ years; 35 patients & 81 & 12 \\
\hline 14 & Kim et al. ${ }^{23)}(2017)$ & Korea & 175 & 175 & 0 & 0 & 220 & $\begin{array}{l}\text { DAPT for hypo-responder (59.6 } \pm 8.71) \\
\text { modified DAPT for hypo-responder } \\
(60.1 \pm 10.52)\end{array}$ & 139 & 102 \\
\hline 15 & Kim et al. ${ }^{24)}$ (2018) & Korea & 47 & 47 & 0 & 0 & 240 & $\begin{array}{l}\text { Responder }(55.27 \pm 11.49) \\
\quad \text { hypo-responder }(59 \pm 10.71)\end{array}$ & 31 & 6 \\
\hline
\end{tabular}

ECS : extra-cranial stenting, ICS : intra-cranial stenting, PRU : P2Y12 reaction unit, DM : diabetes mellitus, NE : not estimated, DAPT : dual antiplatelet therapy, TAPT : triple antiplatelet therapy 


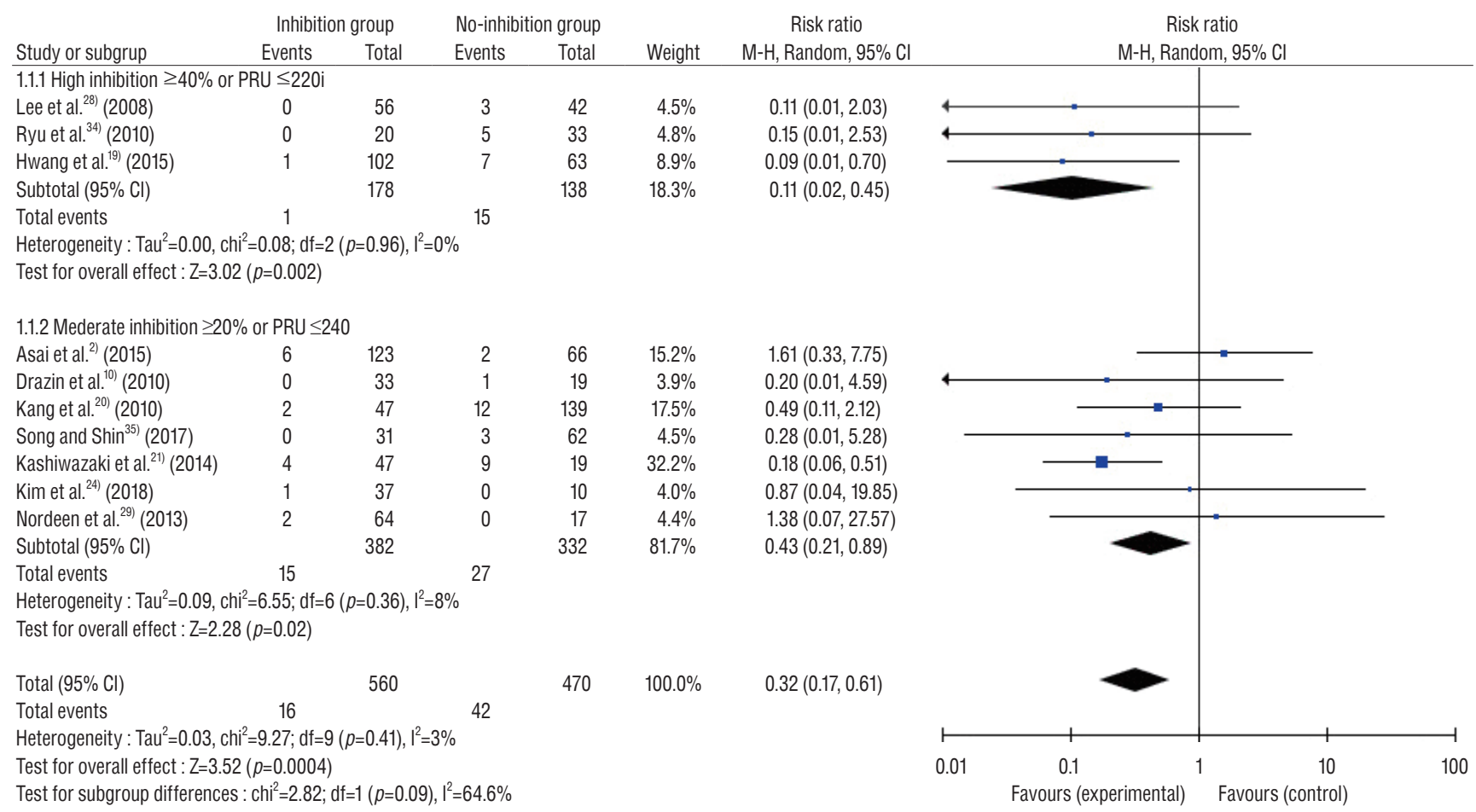

Fig. 2. Comparison of thromboembolic events between no-inhibition group and Inhibition group after dual antiplatelet medication. $\mathrm{Cl}$ : confidence interval, $\mathrm{PRU}: \mathrm{P} 2 \mathrm{Y} 12$ reaction unit.

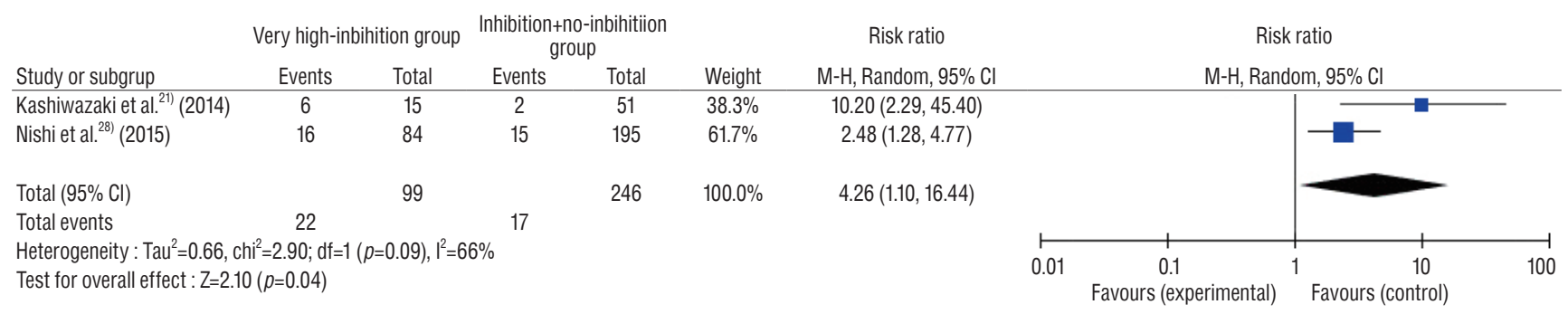

Fig. 3. Comparison of hemorrhagic events between very high-inhibition group and inhibition+no-inhibition group after dual antiplatelet medication. $\mathrm{Cl}$ : confidence interval.

fined as less than $20 \%$ inhibition percentage in one study or more than 180, 213, 220 PRU value in three studies. In the studies by Hwang et al. ${ }^{19}$, in TAPT group, $200 \mathrm{mg}$ of cilostazol was added before the procedure for clopidogrel hypo-responder group with more than 213 value of PRU. The study by Fifi et al. ${ }^{12)}$ was a case-cohort study and in modified DAPT group, the inhibition percentage of PRU was attempted to be adjusted to be more than $20 \%$ by adding more clopidogrel in clopidogrel hypo-responder group. In the study by Wong et al. ${ }^{38)}$, in modified DAPT group, the PRU value was attempted to be adjusted from 120 to 180 by doubling the dose of clopidogrel in clopidogrel hypo-responder group. In the study by Kim et al. ${ }^{23)}$, in modified DAPT group, 10 or $5 \mathrm{mg}$ of prasugrel was replaced from clopidogrel before the procedure for clopidogrel hypo-responder group with more than 220 value of PRU.

Subgroup results divided based on study design were as follows; 1) in the study by Hwang et al. ${ }^{19)}$ which was an randomized control study (RCT), TAPT group exhibited a tendency to decrease the incidence of TE (RR, 0.14; 95\% CI, 0.02-1.13; $p=0.06$ ). In three non-randomized studies (NRS), modified DAPT group had no significant different of TE than standard DAPT group (RR, 0.32; 95\% CI, 0.09-1.18; $p=0.09 ; \mathrm{I}^{2}=41 \%$ ). 


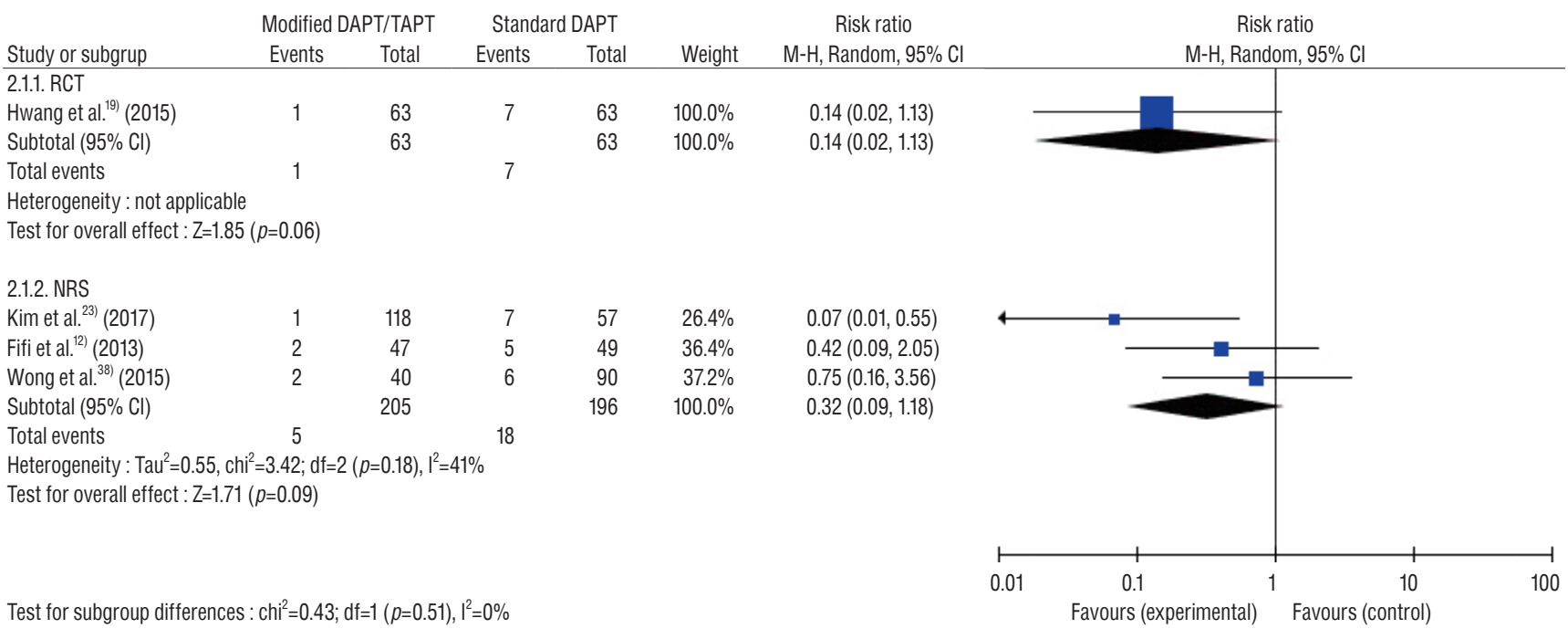

Fig. 4. Comparison of thromboembolic events between modified DAPT/TAPT and standard DAPT after VerifyNow. DAPT : dual antiplatelet therapy, TAPT : triple antiplatelet therapy, $\mathrm{Cl}$ : confidence interval, RCT : randomized control study, NRS : non-randomized studies.

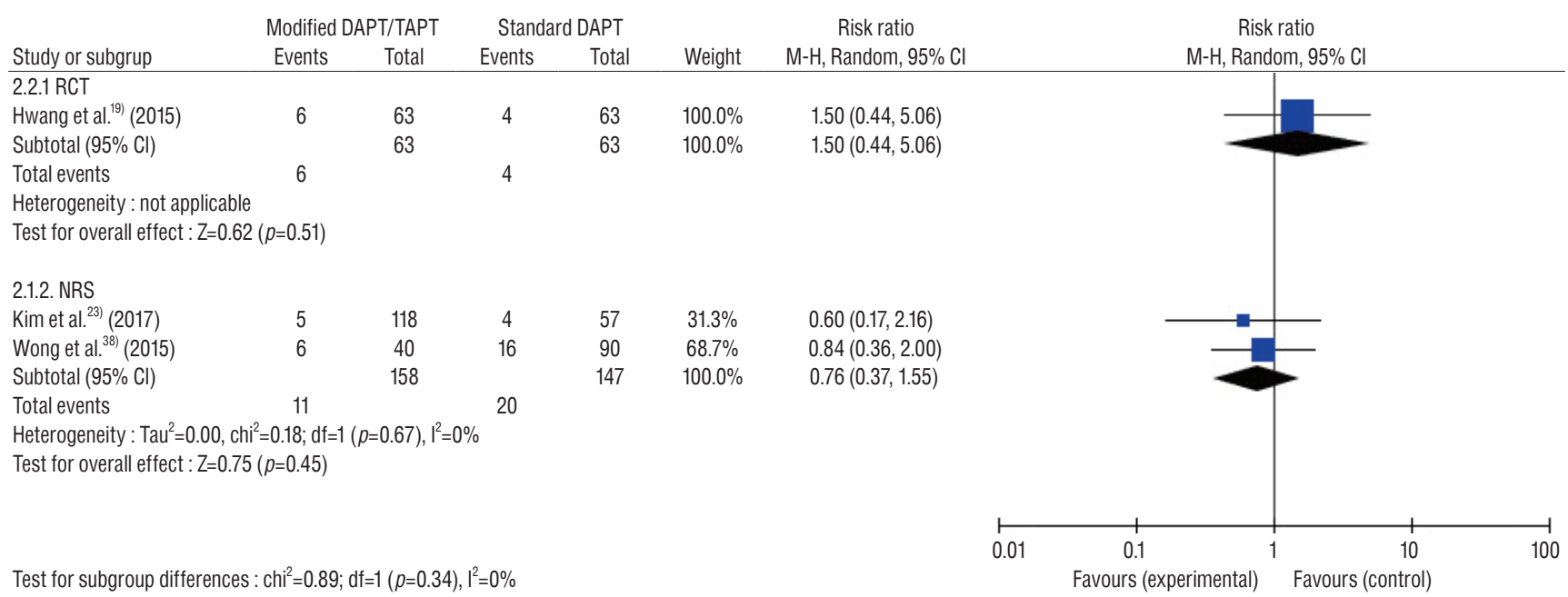

Fig. 5. Comparison of hemorrhagic events between modified DAPT/TAPT and standard DAPT after VerifyNow. DAPT : dual antiplatelet therapy, TAPT : triple antiplatelet therapy, $\mathrm{Cl}$ : confidence interval, RCT : randomized control study, NRS : non-randomized studies.

\section{Result 4. The incidence of HT between modified DAPT or TAPT group and standard DAPT group for no-inhibition group (Fig. 5)}

This HE result was based on three studies. On both RCT and NRS, the incidence of HE was no significant difference between modified DAPT or TAPT group and standard DAPT group $(p>0.05)^{19,23,38)}$.

\section{DISCUSSION}

Our results showed that incidence of TE during the periprocedural period on neurointervention significantly increased when the patient showed clopidogrel resistance in VerifyNow with low heterogenesity $\left(\mathrm{I}^{2}=3 \%\right)$. And incidence of HE during the peri-procedural period significantly increased when the patient showed clopidogrel hyper-responder in VerifyNow, despite this result 2 had moderate heterogenesity $\left(\mathrm{I}^{2}=66 \%\right)$.

We could find that PRU of VerifyNow can be a good pre- 
dictor of peri-procedural complications in neurointervention. In addition, based on the results of subgroup analysis about the incidence of TE according to changes in PRU cut-off value, the incidence of TE was significantly more decreased when the studies was enrolled with high inhibition cut-off value $(>40 \%$ or $<220)$. In other words, in periprocedural TE of neurointervention, threshold effect was evident according to the cut off value depending on the degree of inhibition.

On result 3, four studies compared the results of TE according to the changes in the regimen of antiplatelet therapy due to clopidogrel resistance. According to research design, one study was an RCT and the other three studies were NRS. RCT showed that TAPT group had a relatively lower incidence of TE $(p=0.06)$. In addition, NRSs showed the modified DAPT had a tendency to reduce the incidence of TE with statistical significance ( $R R, 0.32 ; p=0.09$ ). However, there was no significantly different between modified DAPT or TAPT group and Standard DAPT group. It is possible that lack of studies reflect these results. RCT was only one Hwang's study and three NRS also had a different regimen protocol.

On result 4, the modifications to modified DAPT or TAPT regimen for clopidogrel hypo-responder did not significantly increase HE during peri-procedure. So, modified DAPT or TAPT is a useful and safety regimen for clopidogrel hypo-responder to reduce the TE without increasing the HE during peri-procedure.

The results of cardiology study underwent RCT showed the similar result with our study. Gauging Responsiveness with A VerifyNow Assay-Impact on Thrombosis and Safety (GRAVITAS) trial in cardiology also showed that clopidogrel resistance according to PRU level increases myocardiac infarction and thromboembolic risk ${ }^{32)}$. Furthermore, this trial concluded that there was no significant difference between the standard and high-dose clopidogrel group in terms of reduction in the incidence of stent thrombosis or death due to cardiovascular disease or nonfatal myocardial infarction. In addition, the doubling or addition of drugs did not increase intracranial bleeding or severe bleeding events on GRAVITAS trial ${ }^{32)}$. The Assessment by a Double Randomization of a Conventional Antiplatelet Strategy versus a Monitoring-guided Strategy for Drug-Eluting Stent Implantation and of Treatment Interruption versus Continuation One Year after Stenting (ARTIC) study also reported that antiplatelet adjustment using plateletfunction testing before and after coronary stenting did not improve the clinical outcome in patients exhibiting antiplatelet poor response ${ }^{6}$. In addition, a report published by the European Society of Cardiology revealed that there was no evidence that testing and modifying the antiplatelet medication before coronary interventions lead to improvements in the outcomes $^{33)}$. This study was only enrolled in neurointervention procedure (aneurysm coiling and extra- and intra-carotid stenting). Our result showed that despite the effectiveness of PRU on neurointervention is very reliable to predict periprocedural complications, modification antiplatelet regimen according to PRU did not affect the periprocedural TE or HE. This result should be further investigated with more RCT with same protocols such as same PRU, same procedure.

Clinically, we presume that various factors could affect clopidogrel resistance to control clopidogrel resistance and many complex and organic pathways may affect by each steps on coagulation pathway. Recently, diabetes and current cigarette smoking behavior have been studied not only as important risk factors for stroke but also as the factors affecting the antiplatelet effect of clopidogrel. The clopidogrel resistance induced by diabetes mellitus could be explained based on two mechanisms; first, insulin reduces platelet aggregation by inhibition of the P2Y12 pathway, so diabetic patients with a tendency of up-regulation of P2Y12 sensitivity experience high platelet reactivity; and second, diabetes mellitus is an important risk factor for chronic kidney diseases, and chronic kidney diseases are related to high platelet reactivity ${ }^{1,11)}$. Cigarette smoking has a debating on clopidogrel resistance. Although cigarette smoking is the main risk factor for cardiovascular events, cigarette smoking is a known inducer of CYP1A2, which is the isoenzyme for the oxidative step in the conversion of clopidogrel into the active metabolite. Therefore, it has been reported that smokers have lower clopidogrel resistance and higher bleeding risk compared to non-smokers ${ }^{4,9,37)}$.

In addition, many other genetic aspects associated with clopidogrel resistance have been discussed. Carriers of the reduced-function CYP2C19 allele are at a greater risk of developing resistance to clopidogrel ${ }^{13,26)}$. Also, it has been reported that the frequency of carrying reduced-function CYP2C19 allele is not rare in the Asian population, and this fact supports that Asians have a high percentage of clopidogrel hypo-responder. Escalating Clopidogrel by Involving a Genetic Strategy-Thrombolysis In Myocardial Infarction 56 (ELEVATETIMI 5627) study failed to improve platelet inhibition in 
cardiovascular patients with CYP2C19² heterozygote after high dose clopidogrel therapy ${ }^{17}$. Many studies suggested that the use of other drug with another mechanism of action such as cilostazol or prasugrel, and ticagrelor might be a good options to prevent the $\mathrm{TE}^{5,13-15,18}$.

Stent-assisted coiling or the use of flow-diverter stents have been increasing nowadays. Whereas studies on the use of modified DAPT or TPAT regimen to prevent TE are rare in neurointervention. Therefore, further research on this topic involving RCT should be undertaken.

This study has several limitations. First, a cut-off value of PRU was different for each study. Although each study provides reasonable criteria based on the cardiology study or other prior criteria, no absolute cut off value in neurointervention has been determined yet. So, we performed subgroup analysis, which revealed that the incidence of TE had threshold effect according to the cut-off level of PRU. Second, we excluded the case of the flow-diverter stent which has been recently employed as a new neurointervention device. As flow-diverter stents have higher metal coverage, it is more thrombogenic than other stents. Additionally, the flow-diverter stent is not widely used yet and it usually has a different treatment indication such as a large or a recurrent aneurysm. Accordingly, we excluded the studies on flow-diverter stent because of the possible heterogeneity in the current study $y^{3,7,8,36)}$. Third, on result 3 and 4 about modification of regimen DAPT for hypo-repsonder of clopidogrel, only one RCT was found. So, the study about modification of regimen DAPT should be investigated.

\section{CONCLUSION}

As a predictor of peri-procedural TE or HE of neurointervention, PRU level through VerifyNow is a very useful and effective tool. In addition, in periprocedural TE of neurointervention, higher inhibition of clopidogrel result the lower periprocedural TE with threshold effect according to the cut off value depending on the degree of inhibition. Modified DAPT or TAPT to prevent TE in clopidogrel hypo-responders could not reduce the incidence of TE. Additional research is needed on this topic and other mechanisms involved in genetic study or other risk factors should be further investigated.

\section{CONFLICTS OF INTEREST}

No potential conflict of interest relevant to this article was reported.

\section{INFORMED CONSENT}

This type of study does not require informed consent.

\section{AUTHOR CONTRIBUTIONS}

\author{
Conceptualization : HJK, JSO \\ Data curation : HJK, JSO \\ Formal analysis : HJK, JSO \\ Funding acquisition : HJK, JSO, SQP, SMY, HSA, BTK \\ Methodology : HJK, JSO \\ Project administration : JSO \\ Visualization : JSO \\ Writing - original draft : JSO \\ Writing - review \& editing: HJK, JSO, SQP, SMY, HSA, \\ BTK
}

\section{ORCID}

$\begin{array}{ll}\text { Hyun Jung Kim } & \text { https://orcid.org/0000-0003-2018-2385 } \\ \text { Jae Sang Oh } & \text { https://orcid.org/0000-0003-4570-6763 } \\ \text { Sukh Que Park } & \text { https://orcid.org/0000-0001-5899-179X } \\ \text { Seok Mann Yoon } & \text { https://orcid.org/0000-0002-0048-6309 } \\ \text { Hyeong Sik Ahn } & \text { https://orcid.org/0000-0002-2084-7466 } \\ \text { Bum Tae Kim } & \text { https://orcid.org/0000-0003-2646-8165 }\end{array}$

\section{-Acknowledgements}

This research was supported by Soonchunhyang University Research Fund.

This research was supported by the Bio \& Medical Technology Development Program of the National Research Foundation (NRF) funded by the Korean government (MSIT) (NRF2019M3E5D1A02069061). 


\section{-Supplementary materials}

The online-only data supplement is available with this article at https://doi.org/10.3340/jkns.2019.0082.

\section{References}

1. Angiolillo DJ, Shoemaker SB, Desai B, Yuan H, Charlton RK, Bernardo E, et al. : Randomized comparison of a high clopidogrel maintenance dose in patients with diabetes mellitus and coronary artery disease: results of the optimizing antiplatelet therapy in diabetes mellitus (OPTIMUS) study. Circulation 115 : 708-716, 2007

2. Asai T, Miyachi S, Izumi T, Matsubara N, Haraguchi K, Yamanouchi T, et al. : Relationship between low response to clopidogrel and periprocedural ischemic events with coil embolization for intracranial aneurysms.

J Neurointerv Surg 8 : 752-755, 2016

3. Bender MT, Lin LM, Colby GP, Lubelski D, Huang J, Tamargo RJ, et al. : P2Y12 hyporesponse (PRU>200) is not associated with increased thromboembolic complications in anterior circulation Pipeline. J Neurointerv Surg 9 : 978-981, 2017

4. Berger JS, Bhatt DL, Steinhubl SR, Shao M, Steg PG, Montalescot G, et al. : Smoking, clopidogrel, and mortality in patients with established cardiovascular disease. Circulation 120 : 2337-2344, 2009

5. Biondi-Zoccai G, Lotrionte M, Agostoni P, Abbate A, Romagnoli E, Sangiorgi $G$, et al. : Adjusted indirect comparison meta-analysis of prasugrel versus ticagrelor for patients with acute coronary syndromes. Int J Cardiol $150: 325-331,2011$

6. Collet JP, Cuisset T, Rangé G, Cayla G, Elhadad S, Pouillot C, et al. : Bedside monitoring to adjust antiplatelet therapy for coronary stenting. $\mathbf{N}$ Engl J Med 367 : 2100-2109, 2012

7. Daou B, Starke RM, Chalouhi N, Barros G, Tjoumakaris S, Rosenwasser $\mathrm{RH}$, et al. : P2Y12 reaction units: effect on hemorrhagic and thromboembolic complications in patients with cerebral aneurysms treated with the pipeline embolization device. Neurosurgery 78 : 27-33, 2016

8. Delgado Almandoz JE, Crandall BM, Scholz JM, Fease JL, Anderson RE, Kadkhodayan $Y$, et al. : Pre-procedure P2Y12 reaction units value predicts perioperative thromboembolic and hemorrhagic complications in patients with cerebral aneurysms treated with the pipeline embolization device. J Neurointerv Surg 5 : iii3-iii10, 2013

9. Desai NR, Mega JL, Jiang S, Cannon CP, Sabatine MS : Interaction between cigarette smoking and clinical benefit of clopidogrel. J Am Coll Cardiol 53 : 1273-1278, 2009

10. Drazin D, Choulakian A, Nuño M, Kornbluth P, Alexander MJ : Body weight: a risk factor for subtherapeutic antithrombotic therapy in neurovascular stenting. J Neurointerv Surg 3 : 177-181, 2011

11. Ferroni $P$, Basili $S$, Falco $A$, Davì $G$ : Platelet activation in type 2 diabetes mellitus. J Thromb Haemost 2 : 1282-1291, 2004

12. Fifi JT, Brockington C, Narang J, Leesch W, Ewing SL, Bennet $H$, et al. : Clopidogrel resistance is associated with thromboembolic complications in patients undergoing neurovascular stenting. AJNR Am J Neuroradiol $34:$ : 716-720, 2013

13. González A, Moniche F, Cayuela A, García-Lozano JR, Torrecillas F, Escudero-Martínez I, et al. : Effect of CYP2C19 polymorphisms on the platelet response to clopidogrel and influence on the effect of high versus standard dose clopidogrel in carotid artery stenting. Eur J Vasc Endovasc Surg 51 : 175-186, 2016

14. Gurbel PA, Bliden KP, Butler K, Tantry US, Gesheff T, Wei C, et al. : Randomized double-blind assessment of the ONSET and OFFSET of the antiplatelet effects of ticagrelor versus clopidogrel in patients with stable coronary artery disease: the ONSET/OFFSET study. Circulation 120 : 2577-2585, 2009

15. Ha EJ, Cho WS, Kim JE, Cho YD, Choi HH, Kim T, et al. : Prophylactic antiplatelet medication in endovascular treatment of intracranial aneurysms: low-dose prasugrel versus clopidogrel. AJNR Am J Neuroradiol 37 : 2060-2065, 2016

16. Higgins JP, Altman $D G$, Gøtzsche $P C$, Jüni $P$, Moher $D$, Oxman $A D$, et al. : The cochrane collaboration's tool for assessing risk of bias in randomised trials. BMJ 343 : d5928, 2011

17. Hochholzer W, Ruff CT, Mesa RA, Mattimore JF, Cyr JF, Lei L, et al. : Variability of individual platelet reactivity over time in patients treated with clopidogrel: insights from the ELEVATE-TIMI 56 trial. J Am Coll Cardiol 64 : 361-368, 2014

18. Hokimoto S, Mizobe M, Akasaka T, Arima Y, Kaikita K, Nakagawa K, et al. : Impact of CYP2C19 polymorphism and proton pump inhibitors on platelet reactivity to clopidogrel and clinical outcomes following stent implantation. Thromb Res 133 : 599-605, 2014

19. Hwang G, Huh W, Lee JS, Villavicencio JB, Villamor RB Jr, Ahn SY, et al. : Standard vs modified antiplatelet preparation for preventing thromboembolic events in patients with high on-treatment platelet reactivity undergoing coil embolization for an unruptured intracranial aneurysm: a randomized clinical trial. JAMA Neurol 72 : 764-772, 2015

20. Kang HS, Kwon BJ, Kim JE, Han MH : Preinterventional clopidogrel response variability for coil embolization of intracranial aneurysms: clinical implications. AJNR Am J Neuroradiol 31 : 1206-1210, 2010

21. Kashiwazaki D, Kuwayama N, Akioka N, Hayakawa Y, Kuroda S: The roles and issues of P2Y12 percent inhibition assessed by VerifyNow assay for patients undergoing neurointervention: a prospective study. J Stroke Cerebrovasc Dis 23 : 1830-1836, 2014

22. Kim BJ, Kwon JY, Jung JM, Lee DH, Kang DW, Kim JS, et al. : Association between silent embolic cerebral infarction and continuous increase of P2Y12 reaction units after neurovascular stenting. J Neurosurg 121 : 891-898, 2014

23. Kim CH, Hwang G, Kwon OK, Ban SP, Chinh ND, Tjahjadi M, et al. : P2Y12 reaction units threshold for implementing modified antiplatelet preparation in coil embolization of unruptured aneurysms: a prospective validation study. Radiology 282 : 542-551, 2017

24. Kim MS, Park ES, Park JB, Lyo IU, Sim HB, Kwon SC : Clopidogrel response variability in unruptured intracranial aneurysm patients treated with stent-assisted endovascular coil embolization : is follow-up clopidogrel response test necessary? J Korean Neurosurg Soc 61 : 201-211, 
2018

25. Lee DH, Arat A, Morsi H, Shaltoni H, Harris JR, Mawad ME : Dual antiplatelet therapy monitoring for neurointerventional procedures using a point-of-care platelet function test: a single-center experience. AJNR Am J Neuroradiol 29 : 1389-1394, 2008

26. Mega JL, Hochholzer W, Frelinger AL 3rd, Kluk MJ, Angiolillo DJ, Kereiakes DJ, et al. : Dosing clopidogrel based on CYP2C19 genotype and the effect on platelet reactivity in patients with stable cardiovascular disease. JAMA 306 : 2221-2228, 2011

27. Mehran R, Rao SV, Bhatt DL, Gibson CM, Caixeta A, Eikelboom J, et al. : Standardized bleeding definitions for cardiovascular clinical trials: a consensus report from the Bleeding Academic Research Consortium. Circulation 123 : 2736-2747, 2011

28. Nishi H, Nakahara I, Matsumoto S, Hashimoto T, Ohta T, Sadamasa N, et al. : Platelet reactivity and hemorrhage risk in neurointerventional procedures under dual antiplatelet therapy. J Neurointerv Surg 8 : 949-953, 2016

29. Nordeen JD, Patel AV, Darracott RM, Johns GS, Taussky P, Tawk RG, et al. : Clopidogrel resistance by P2Y12 platelet function testing in patients undergoing neuroendovascular procedures: incidence of ischemic and hemorrhagic complications. J Vasc Interv Neurol 6 : 26-34, 2013

30. Pierot $L$, Wakhloo AK : Endovascular treatment of intracranial aneurysms: current status. Stroke 44 : 2046-2054, 2013

31. Prabhakaran $S$, Wells KR, Lee VH, Flaherty CA, Lopes DK : Prevalence and risk factors for aspirin and clopidogrel resistance in cerebrovascular stenting. AJNR Am J Neuroradiol 29 : 281-285, 2008
32. Price MJ, Berger PB, Teirstein PS, Tanguay JF, Angiolillo DJ, Spriggs D, et al. : Standard- vs high-dose clopidogrel based on platelet function testing after percutaneous coronary intervention: The GRAVITAS randomized trial. JAMA 305 : 1097-1105, 2011

33. Rosano GMC, Seferovic $P$ : 2017 ESC guidelines focus on dual antiplatelet therapy. Eur Heart J Cardiovasc Pharmacother 4 : 131-132, 2018

34. Ryu DS, Hong CK, Sim YS, Kim CH, Jung JY, Joo JY : Anti-platelet drug resistance in the prediction of thromboembolic complications after neurointervention. J Korean Neurosurg Soc 48 : 319-324, 2010

35. Song J, Shin YS : Antiplatelet drug resistance did not increase the thromboembolic events after stent-assisted coiling of unruptured intracranial aneurysm: a single center experience of 99 cases. Neurol Sci $38: 879$ 885, 2017

36. Tan LA, Keigher KM, Munich SA, Moftakhar R, Lopes DK : Thromboembolic complications with pipeline embolization device placement: impact of procedure time, number of stents and pre-procedure $\mathrm{P} 2 \mathrm{Y} 12$ reaction unit (PRU) value. J Neurointerv Surg 7 : 217-221, 2015

37. Ueno M, Ferreiro JL, Desai B, Tomasello SD, Tello-Montoliu A, Capodanno $D$, et al. : Cigarette smoking is associated with a dose-response effect in clopidogrel-treated patients with diabetes mellitus and coronary artery disease: results of a pharmacodynamic study. JACC Cardiovasc Interv 5 : 293-300, 2012

38. Wong P, Tesoro E, Aletich V, Alaraj A : Accumetrics-based clopidogrel dosing in endovascular neurosurgery. Neurol Res 37 : 998-1005, 2015 